ScIDice

\section{Removable Partial Denture Designing: Variation of Hard and Soft Tissue Anatomy and Maxillary Major Connector Selection}

ISSN: $2377-8075$

\title{
Gad MM*
}

Department of Substitutive Dental Sciences, College of Dentistry, University of Dammam, Dammam, Saudi Arabia.

\section{Abstract}

Removable partial denture (RPD) is one of the various treatment options available for the replacement of teeth for partially edentulous patients. The major connector of an RDP is the component that connects the different parts of the RPD as well as can achieve numerous functions and influence the success of RPD. The variety of anatomic considerations related to the shape of the palate and gingival conditions may affect selection of maxillary major connector. The objective of this review is to screen literature for data related to maxillary major connector and factors affecting its selection. Up to 2016, Database on Google scholar and PubMed were conducted using the keywords "RPD design; maxillary major connector; palatal contour; gingival and periodontal condition". Conclusion, anatomy of the palate and different tissue conditions may affect the major connector selection, so the RPDs Designers should be familiar with those structures during major connector selection.

Keywords: Removable Partial Denture; RPD Design; Maxillary Major Connector Framework; Shape of the Palate.

\section{Introduction}

There are various treatment options in replacing missing teeth for the partially edentulous mouth as removable partial dentures (RPD) which are an effective and reasonable treatment modality to restore function and aesthetics [1]. RPD success mainly depends on proper design and components selection. Maxillary major connector (MMC) is RPD component that fulfill various functions and important for RPD effectiveness. Patient's acceptance, oral anatomy, and fundamental RDP design were considered important factors for MMC design and dimensions [2]. The intimate contact between the MMC and the palatal mucosa and wide mucosal coverage improves retention and stability of RPD [1]. Selection of the most acceptable and effective MMC still need clarifications according to clinical situations. Database on Google scholar and PubMed (literatures search and surveys) were conducted using the key words "RPD design; maxillary major connector; palatal contour; gingival and periodontal condition", including additional related articles and links revealed a total of
75 publications for this review. The purpose of this article is to review literature reporting on maxillary major connector and factors affecting its selection specially the palatal contour and gingival conditions.

\section{Definition}

The MC is the most important component of the partial denture framework to which all other components are attached [3, 4].

\section{Requirements}

The choice of MMC type is based upon requirements include: rigidity, function, and hygiene [5].

Rigidity: Rigidity is the major requisite of MCs, through which stresses that are applied to any component of the RPD are efficiently distributed over the entire supporting area, including abutment teeth, underlying bone and soft tissues in addition to resist

*Corresponding Author:

Mohammed M. Gad BDS, MSc

Department of Substitutive Dental Sciences, College of dentistry, University of Dammam, Dammam, Saudi Arabia, P.O. Box 1982 Dammam 31441

Tel: +966592502080

Fax: +966138572624

E-mail: dr.gad@hotmail.com

Received: March 30, 201

Accepted: April 20, 2017

Published: April 26, 2017

Citation: Gad MM (2017) Removable Partial Denture Designing: Variation of Hard and Soft Tissue Anatomy and Maxillary Major Connector Selection. Int J Dentistry Oral Sci. 4(4), 457-463. doi: http://dx.doi.org/10.19070/2377-8075-1700090

Copyright: Gad $\mathbf{M M}^{\circ}$ 2017. This is an open-access article distributed under the terms of the Creative Commons Attribution License, which permits unrestricted use, distribution and reproduction in any medium, provided the original author and source are credited. 
flexing and torquing forces and the effectiveness in transmitting applied occlusal forces to the both sides of the framework [4, 6-11]. Rigidity has been investigated by flexibility or amount of deflection. The magnitude and direction of the deflection that the prosthesis undergoes depends on the rigidity of the major connector [4]. A flexible MC causes an unequal distribution of forces with changes in their intensity and may cause damage to the supporting structures [3]. With work load, MC will flex and cause movements of extension base toward the sub-basal structures at its middle and repeatedly pressing the mucosal covering resulting in localized inflammation followed by edema and underlying bone is involved may eventually produce a perforation of the mucosal pad and infrequently a sequestrum may be exfoliated [12]. The width and thickness of MCs were have considerations majority where decreased width and thickness displayed more deflection [6].

These deflections (flexibility) can be controlled by using a cast connector and employ a less flexible alloy; increasing the bulk when the connector is long; include two planes; maximum soft tissues coverage; proper selection of direct retainers combined with other components placement in the further most useful position; additional occlusal rest [4, 6, 13]. Bhojaraju et al., in 2014 have been used the three-dimensional finite element analysis (FEA) to study the deflections of MMCs and found that the maximum displacements in the vertical direction under a specified vertical load was found in class I full palate while, smallest maximum displacement was found in class IV Anteroposterior palatal strap [4]. Ozkan and Aydin in 2001 used stereo photogrammetry to study the deflection properties of palatal plate, U-shaped plate, palatal strap, and AP bar MMCs for maxillary Kennedy Class I RPDs under periodic loading and fond that, the least deformation was recorded with the AP but some micro-cracks were located at the depth of the hard palate. On the other side, the U-shaped showed the highest deflection without micro-cracks [14]. Finally, MCs rigidity is the prime request to reveal proper and effective RPDs which could be achieved through increasing the thickness and width without adverse effect on all supporting structures and patient's comfort.

Function: The main function of a MC is to join other components of RPD framework and transmits the force from point of loading on the artificial teeth to both sides as it crossed the arch providing cross arch stability $[5,11]$. In addition to other functions such as distribution of forces applied on it throughout the arch; minimizing the torque on the teeth [15]; contribute to stability and effectively controlling the movement of RPDs; reducing stresses on abutment teeth and residual alveolar ridges under denture bases $[5,11,15]$; contributes to the support from the horizontal part of the palate and bracing from vertical side, distributing the functional stresses broadly to the teeth and palatal tissues due to the intimate contact to the underlying palatal mucosa [5, 16]. To be effective and successfully perform those functions, MC should be rigid.

Hygiene: RPDs should be self-cleansable and properly designed to avoid plaque accumulation [5]. Periodic checkup and oral hygiene measures of RPDs' users are essential to improve periodontal health and prosthesis longevity [17]. In contrary, Cosme et al., reported that there is no relation between oral hygiene and prosthesis $[5,18]$. As the MCs in intimate contact with oral mucosa, poor oral hygiene may increase the incidence of caries, Plaque accumulation, and periodontal diseases in RPD users. These harm- ful effects on dental and supporting tissues may be alleviated if oral hygiene program is commenced.

\section{Types of Major Connector}

Optimum success of RPDs depend on major connector type and specification $[15,16]$ so, it's essential to review MC types. Hence load application on the prosthesis will result in deflection, these MCs have a specific thickness and width respectively so that they can withstand both axial and tangential load during mastication $[4,22]$. The variations of MCs (narrow or wide, thin or thick) depends upon its relation to adjacent tissues, location, and the need for support and reasonable rigidity RPDs [19, 20]. The choice of $\mathrm{MC}$ lies between a bar, strap, a plate or a combination of bars [5]. As the $\mathrm{MC}$ crosses the palate in various positions, it can be classified according to form, thickness, and position into bar, A-PP bar, strap, A-PP strap, U-shaped, and plate [5, 15, 19-21]. The MCs used in maxillary RPD are mainly the A-PP strap, full palatal plate, palatal strap and u-shaped while bar type lest used [5, 20].

Bar: Bar is MC with least anteroposterior width varies from $4-8 \mathrm{~mm}$. Due to the decreased width; palatal bar to have the necessary rigidity for cross-arch distribution of stress and provide support in addition to should be symmetrically and have concentrated bulk. Unfortunately, this bulk changes the palatal contour; therefore, it is highly objectionable to the patient [15]. It could be used instead of a strap according to saddle area extension without objectionable bulk [23]. For many years, the palatal bar was one of the most widely used MMCs and has been described as the most broadly used and the most chosen MMC [15]. Although few advantages of bar (rigidity and less tissue coverage), it is limited to short span Class III applications. In addition, the palatal bar should not be placed anterior to the second premolar position; otherwise its bulk may produce noticeable discomfort and alteration of speech [24].

$\boldsymbol{A}-\boldsymbol{P}$ bar: A-P bar formed of anterior and posterior bars joined by flat longitudinal elements on each side of the palate [8]. This configuration gives the effect of a circle and is considerably more rigid than any of the individual elements. The two bars, lying in different planes, produce a structurally strong L-beam effect thus making the main advantage of an A-P bar is its rigidity [22] in addition to excellent rigidity compared to other MMCs [14, 25]. The A-P bar minimizes soft tissue coverage, yet provides exceptional resistance to deformation. The A-P bar may be used when support is not a major consideration and when the anterior and posterior abutments are widely separated. A-P bar also may be chosen for patients with large palatal to that cannot be removed for health reasons [26]. Although its advantages, is frequently uncomfortable. The bulk and contour of the connector may be bother some to the tongue and may interfere with phonetics. Moreover, because of its limited contact with the palatal tissues, the anteroposterior palatal bar derives little support from the bony palate. Consequently, its use may be contraindicated in patients with reduced periodontal support [25]. As a general rule, the anteroposterior palatal bar should not be considered the first choice for a maxillary major connector. It should be selected only after other choices have been considered and eliminated [26].

Strap: Strap is a transverse palatal cover, normally $8-12 \mathrm{~mm}$ in width, and may extend up to $20 \mathrm{~mm}$ with proper thickness [21]. Pienkos et al., stated that the PS with adequate rigidity should have 
a width of at least $8 \mathrm{~mm}$ with an increase in size for distal extensions and can be used for most designs [2]. The PS with smaller widths demonstrated greater displacements and affected the RPD effectiveness [11]. Eto et al., and Inoue et al., have been analyzed the relation between PS width and the displacements and found that PS widths of more than $18 \mathrm{~mm}$ revealed comparable rigidity, broad bar while, increased width called a modified palatal plate [5, $15,20]$. PS with more tissue coverage in this section contributed to support and distributes masticatory stress over a wide area all advantage make it the preferred choice for the maxilla $[2,11]$.

A-PP strap: A-PP strap comprise two transverse palatal straps ( 8 to $10 \mathrm{~mm}$ width) and two longitudinal parallel straps $(6 \mathrm{~mm}$ width) [21]. This circle configuration ("L-beam" effect) could be improved the connector rigidity because the straps are in 2 different planes [2] therefore it favorite used for most maxillary partially edentulous situation [4]. This was confirmed by studies, in which the A-PP strap had the highest rigidity and also showed the least deformation of the MMCs tested [6-8, 22, 28, 29]. In addition to its uses in most maxillary partial denture designs, indicated in cases with inoperable palatal torus [26].

U-shape: All major connector designs should have the potential to reduce torquing forces delivered to the abutments by loading a removable partial denture distal extension [22]. Framework rigidity is also influenced by the design of the major connector. $\mathrm{U}$ shaped palatal bar was the most flexible maxillary major connector $[6,28]$. The major connector must be rigid in order to perform its functions with maximum efficiency. The distal extension U-shaped connector demonstrates increased flexibility due to the open ends [29]. This increased flexibility may have adverse effects on force transmission to the abutment teeth [35], so the U-shaped design is less desirable [22]. However, it is the most commonly used major connectors in the maxilla [21]. The U-shape is indicated for use in cases with an inoperable palatal torus, Kennedy class III with multiple modifications [31, 8], Kennedy class IV rotational-path RPDs $[32,33]$, and in cases with an overstated gag reflex and unable to accepta bar or strap crossing their posterior palate. Although often used arbitrarily, the U-shape major connector should not be the design of first choice, because other connectors may serve more effectively $[29,31,34]$.

The U-shaped palatal bar was the most flexible [36]. Aiming to improve the U-shape rigidity, double thickness of the anterior strap of a U-shaped enhanced the rigidity of the framework loads [30]. Also, Ben-ur et al., stated that, the arch length of U-shape should be planned as short as possible without compromising occlusal support [22]. To achieve maximum resistance to functional forces, the major connector should be designed to transverse the maxilla opposite the edentulous ridge which is the area of maximum load. Additionally, it is wise to end the dentulous side at the first molar [22]. In addition, Green and Hondrum reported that, as the length of arch increased the flexibility increased. Therefore, the addition of posterior strap, increasing the thickness and width of anterior strap improve the rigidity subsequently, effective in counteracting the torsion load on abutment teeth [30].

Ramakrishnan and Singh used three-dimensional FEA study different stress patterns in the U-shaped major connector designs, palatal mucosa and periodontal ligaments and reported that, lateral forces generate greater stress than the vertical forces in the palatal mucosa and the periodontal ligaments [37]. Design modification (double-thickness) exhibits the least stress in the U-shaped connector which delivered the least stress to the palatal mucosa and ligaments. Therefore, it can be considered for use in clinical situations of Kennedy class IV situations as it exhibits the secondbest, least internal stress under loading and, also, is reasonably rigid as it extends in three planes of the hard palate [30, 37]. But, its use may produce slight alterations in the phonetic abilities of the patient. It also delivers greater stress to the underlying palatal mucosa and periodontal ligament when compared with other designs. This may produce areas of stress concentration in the palatal mucosa and ligament. Therefore, recalling patients for visits on a half-yearly basis would be helpful in assessing the soft tissue alterations, if any $[22,30,37]$. Although, the U-shaped palatal connector reflected the least favorable design is the most regularly used. This might mean that dental technicians are more familiar with the construction of this major connector or its minimal palatal coverage shown patient's comfortable [21].

Plate: Palatal Plates usually extended and offer more palatal coverage than straps [21]. Although there are controversies about what constitutes the dimensions of plates in the upper arch [19]. A typical example of palatal plate indication is a Kennedy class $\mathrm{I}$ and wide maxillary edentulous areas when retention and maximum support were needed [21]. But the main disadvantage is the maximum tissue coverage which may annoy the patient and altered phonetics. Moreover, its contraindication in the presence of palatal tours [26].

Based on the previous section, the understanding and familiarization with different type of MMCs and their specifications according to different oral condition, is a prime request for proper selection of MMCs otherwise faulty design and RPDs failures.

\section{Factor Affecting Major Connector Selection}

The greater variation in shape and locations of MMCs is due to wide area of tissue covered offered by the hard palate [5]. The choice of connector type is based upon Anatomical consideration; functions, rigidity, hygiene, and patient acceptability were collectively a decision-making factor for suitable connector selection $[5,24]$.

\section{Anatomical Constraints:}

Shape of the palate(width and depth): As the shape of the dental arch and palate affect the rigidity of a major connector, the choice of the shape and location of major connectors is greater in the upper jaw because of the larger area available for coverage offered by the hard palate [5]. The location and areas of tissue coverage by a major connector is of utmost importance, as these features will affect the acceptability of the prosthesis and its eventual performance $[25,42]$. The maxillary major connector can be designed to take advantage of the structure of the palate using various slopes, namely the anterior slope or the sagittal slope, palatal vault and lateral or vertical slopes of the palate. This is the L-bar principle used in rigid engineering structure, which states that forces transmitted on more than one plane are counteracted more easily and greater rigidity can be obtained [37]. This rigidity is mandatory to protect the soft tissues, provide vertical support, achieve indirect retention wherever it is indicated, and also to maintain patient comfort [5]. The rigidity of MMCs can be improved by using the hard palate as an area of support [14]. 
However, distribution of tactile sensory spots throughout the palate is dense in the anterior portion and sparse in the deepest part of the palatine arch [14]. Therefore, Campbell stated that, the least amount of gingival tissue coverage, the most comfortable MMC [45]. Hallikerimath et al., used a FEA to evaluate the deflection of PS major connector as influenced by different shapes of palatal vault (deep, shallow, wide, narrow) and concluded that, the maximum displacement is seen in wide and shallow models. This suggests increasing the anteroposterior width of the palatal strap. However, in narrow model deflection was smaller comparatively with other models. This suggests decreasing the anteroposterior width of the palatal strap. In a given maxillary Class II situation MMC with different palatal shapes, wide model, and shallow model were least rigid frameworks. While, average model had minimum values hence; average model was most favorable design among the five finite models [44]. With a wide and shallow palate, it is necessary to design a reinforced palatal strap. With a narrow palate, the anteroposterior width of the palatal strap can be narrower. With a deep palate, it is not necessary to change the palatal strap design according to the palatal shape [42]. Pallegama et al., found that, the thin and wide design was significantly preferred to the thick and narrow design [43]. MMC with minimal dimensions and thickness for a clinically relevant major connector required, while still maintaining the balance between functional strength, comfort to the patient, and the health of the gingival tissue [2]. However, the individual predilections of patients may not be an appropriate basis for an attempt to find a 'best design' applicable to all patients [43].

Palatal tori: Existing Palatal tours affect the design of RPD depends upon its dimension and location [26]. Studies have shown that AP strap may be used for most maxillary partial denture designs and when small Tori are present. It has the circle and Lbeam effect. It should be at least $8 \mathrm{~mm}$ in width for optimum rigidity [34]. With large palatal torus, AP bar may be used while, large inoperable palatal torus extended to soft palate, U-shape major connector is indicated asit interfere with a framework of another design $[32,33]$.

Saddle area: The length of the span being covered and curvature of the palate are critical factors that affect the rigidity of MCs [48]. Moreover, the framework fit can differ according to the span of the edentulous ridge and framework fabrication technique [49]. Judicious distribution of forces between soft and hard tissues depend on the rigidity of components of RPDs particularly MC. Properly selected MC are most likely offer a favorable distribution of force and maintain the integrity of the periodontal and the ridge tissues [50]. For rigidity, MC should be confined to saddle area or more extended if needed but not less otherwise, deflection increased $[44,49]$. In a given maxillary Kennedy Class I and II situation PS or A-PS with different palatal shapes, wide model, and shallow model were least rigid frameworks so increased width as the saddle length increased eventually, indicated palatal plate [44]. While Kennedy class III short to longspan, bar or strap or combinations respectively, which could be changed to modified palatal plate according to extension of saddle area [26, 44]. In Kennedy class IV and class III with multiple modifications, the Ushaped palatal connector is the most frequently used [23, 24, 52].

Gingival and periodontal conditions: Greater attention should be paid to RPD design principles that minimize the risks of tis- sue injury and plaque accumulation in accordance with modern concepts of preventive dentistry [51]. The less amount of tissue that an RDP covers, the greater the advantages in hygiene and health of the soft tissues. The perceived need for structural rigidity must be balanced with the advantages smaller connectors provide to the patient comfort and tissue health [53, 54]. A flexible major connector causes an unequal distribution of forces with changes in their intensity, thus causing damage to the supporting structures $[55,56]$. In comparison with other investigations, the extreme damage the partial denture can produce is from a flexible major connector [6-8]. The gingivae are the most susceptible to injury from the stress induced by a removable prosthesis. Even minor contacts seem to promote an unfavorable reaction in these areas $[53,55,56]$. Inflammation in the areas of contacts made by the MC specially plated one, which must cross the gingiva is soon followed by edema. As the structure becomes distended, the pressure increases and the vicious circle of retrogressive change get established. The end result is a resorption of the adjacent alveolar process with a pocket formation. Loosening of the abutment follows, and as the bone level is lowered, the tilting and twisting stresses on the abutment become more and more of an overload. As the abutment tilts, the impingement of the periodontium in areas of compression will closely follow $[57,58]$. To avoid this, during the first visit the patient should be thoroughly examined regarding presence of subgingival calculus. Such deposits are at times the cause of this irritation because as the gingivae are pressed away from the cervical area by the accumulating mass, they are pressed against the overpassing units of the prosthesis. Proper subgingival scaling and root planning should be performed [59]. Other preventive step considered is the proper occlusal rest preparation. Without adequate occlusal rest stops, there can be gingival impingement in these crossing areas [60]. The gingival response to various types of RPDs depict that the denture made with no gingival relief had the most associated pathology [53]. At the time of construction, a slight relief should be made at each gingival crossing. Particular care should be given to the matter of rounding the edges of the prosthesis, which are adjacent to or cross the gingivae [53]. The second fundamental requirement of a $\mathrm{MC}$ is that it must not permit impingement upon the free gingival margins of the remaining teeth. The marginal gingivae are highly vascular and susceptible to injury from sustained pressure. For this reason, care should be exercised during the design and fabrication of removable partial dentures. In the maxillary arch, the borders of a major connector should be located at least $6 \mathrm{~mm}$ from the free gingival margins. The borders should run parallel to the gingival margins of the remaining teeth $[3,5,26]$. In some cases if the superior border of MMC was fabricated away from free gingival margin by $3 \mathrm{~mm}$ or $2 \mathrm{~mm}$ it could be positive results for design as it allows metal extension and change the MC type, but it could affect the gingiva. In fact this point was neglected in the literatures where no clinical studies on the relation between free gingival margin and superior border of MCs. If the gingival margins must be crossed, they should be crossed at right angles to minimize coverage of the delicate marginal tissues. Where the major connector crosses a gingival margin, relief must be provided between the metal and soft tissues. If relief is not provided, inflammation of the soft tissues will result $[23,28]$.

Clinically, RPD can increase the risk of plaque, gingivitis, and caries especially root ones, in patients who wear them; however, the risk of periodontitis is not obviously increased by them $[18,61]$. In a study done by Janaina et al., it was concluded that RPDs en- 
hanced tooth mobility, diminished prevalence of caries and did not induce the fractures of abutments [62]. For RPDs longevity and improve periodontal health in RPDs' users, satisfactory and regular oral hygiene conditions checkups were required [17].

Patient comfort and satisfaction: MC design does influence the ultimate success of treatment for patients. Patient acceptance and satisfaction depend upon logical and purposeful placement of major connector borders. Ease of speech, mastication, and swallowing and general comfort are affected by design [45]. Thickening of the posterior strap to permit its narrowing was not clinically feasible. In general, patients adapted best to major connectors that covered the least amount of soft tissues [45]. Arigbede et al, compared subjective patients' reactions to three maxillary major connectors and found that, the metal bar major connector was the most acceptable maxillary major connector while acrylic resin plate was more acceptable than metal plate maxillary major connector. It also confirmed the influence of connector design on patient acceptance of removable partial denture [63]. Thinner designs tended to be preferred to the thicker design by the subjects, while none of the designs were consistently selected as the best design [64]. Over the years, it has been observed that patient's tolerance of the various major connector designs was as great as the number of dentists involved in making the designs [1, 65]. Another survey revealed that design and fabrication standards for RPDs are two main factors in patients' acceptance and their satisfaction $[66,67]$.

Phonetics: RDP user's suffered from speech problems especially with wide and thick MCs. It was found that, speech problem was improved or restored to normal when tissue coverage by the MCwas decreased, such as with a PB or PS [45, 68]. Wada et al., (2011, 2014) investigated the effect of width and cross-sectional shape of MMCs on the accuracy of speech production. The experimental connectors were fabricated to simulate bars (narrow, 8- $\mathrm{mm}$ width) and plates (wide, $20-\mathrm{mm}$ width). Two types of cross-sectional shapes in the sagittal plane were specified: flat and plump edge and concluded that, the width and cross-sectional shape of the connectors had limited effects on the articulation of consonants at the palate $[69,70]$. Also, they evaluated the influence of the major connectors on phonetic function with six test sounds using a speech recognition system. The results of the intelligibility suggest that using the middle type of the major connector on dentures has the least impact on phonetic function. In case the denture is a bilateral design, the M-bar, which can connect the teeth abutment with the shortest line, is recommended from a viewpoint of phonetic function [70]. Proponents of the midpalatal bar suggest that this is a favorable position since it leaves the anterior "playground free and also the posterior region of the palate, which may be contacted by the dorsum of the tongue during speech and swallowing [26]. Palatography conducted for selected consonant sounds showed that the incisal papilla and lateral aspect of the palates were the areas more frequently visited by the tongue [20]. However in another study the mid-palatal bar was reported to be the least preferred of the major connector design because of ready detection of two prominent transverse margins by the tongue [71]. This supports the result obtained in another study where metal borders parallel to the tongue were better tolerated than transverse borders [45]. In addition, it was stated that "a middle palatal bar is usually a source of annoyance to the patient as it is positioned in an area where the tongue makes frequent contact with it during swallowing and speech"
[71]. However amongst the transverse palatal bars that is anterior palatal bar, mid palatal bar and posterior palatal bar, the posterior palatal bar has been documented as the most suitable type of the palatal bars for the following reasons [71]: It is less conspicuous to the tongue than the middle or anterior bar; it often fulfils the function of an indirect retainer; and it is in an area less frequently associated with bony prominence or with thin mucosa. A palatal plate which was otherwise called a strap in a particular publication was described as the connector of choice in most instances [5, 72]. It was however advised that the active speech area should be avoided when possible [72]. However in most studies, patients reported poor tolerance with speech, swallowing and comfort with this type of major connector than any other type [45].

\section{Summary}

The anteroposterior bar connector on the other hand has been described as a configuration that is also commonly used in cases of bilateral bounded saddles [72]. The anterior-posterior lengthening of the denture base provides added stability while the greater the space in between the bars the less irritating they are for the tongue [72]. The anteroposterior bar connector design was referred to as a ring connector by one author [5]. But it has been argued that the ring connector is not quite the same as a combination of anterior and posterior bars, as the palatal aspects of the teeth and their gingivae margins are covered in ring connector [72]. Little has been reported about its interference with normal oral function. The ring connector is bulkier in arrangement than the anteroposterior bar system [73]. It has the advantage of being able to link multiple saddles together, greater stimulation of the palate and can also be used in place of a plate in case of maxillary torus. Its disadvantage is in its coverage of gingival margin and its reported interference with speech and patent's comfort [73]. The double-thickness exhibited the least internal stress under loading, and it is the most rigid one. Therefore, it can be considered for use in clinical situations of Kennedy class IV. But, its use may produce slight alterations in the phonetic abilities of the patient because there is an increase in the weight of the cast partial denture. It also delivers greater stress to the underlying palatal mucosa and periodontal ligament when compared with other designs. This may produce areas of stress concentration in the palatal mucosa and ligament. Therefore, recalling patients for visits on a halfyearly basis would be helpful in assessing the soft tissue alterations, if any. On the other hand, design modification 1 can also be considered for Kennedy class IV situations as it exhibits the second-best, least internal stress under loading and, also, is reasonably rigid as it extends in three planes of the hard palate [37]. The dentist should select the major connector that will best satisfy the requirements for rigidity, retention, support, and bracing for each patient. An additional consideration is the designs that will least interfere with such common functions as speaking, mastication, swallowing, and normal, nonfunctional rest. Comparing maxillary major connector designs during speaking, mastication, swallowing, and normal, nonfunctional rest, the most preferred is the single palatal bar [69].

\section{Conclusion}

Based on this review it could be concluded that:

1. Rigidity of maxillary major connector is mandatory for 
RPDs effectiveness.

2. Rigidity affected by width, thickness, length, configuration cross-sectional shape, and shape of the dental arch and palate as well as the locations, numbers, and extension of edentulous area.

3. Less tissue coverage by decreasing width and double thickness of MCs were proper methods to improve rigidity without affecting speech, phonetics, and Patient comfort.

4. Anatomy of the palate and different tissue conditions may affect the major connector selection, so the RPDs Designers should be familiar with those structures during MC selection.

5. RPDs longevity required Patient education, good oral hygiene and preservation of oral tissues (soft and hard).

6. Relation between free gingival margin and superior border of major connector need more clinical investigations. (Why it should be $6 \mathrm{~mm}$ away from free gingival margin? As this distance affect the major connector selection.

\section{References}

[1]. Frantz WR (1975) Variability in a removable maxillary partial denture design by dentists. J Prosth Dent. 34(6): 625-633.

[2]. Pienkos TE, Morris WJ, Gronet PM, Cameron SM, Looney SW (2007) The strength of multiple major connector designs under simulated functional loading. J Prosthet Dent. 97(5): 299-304.

[3]. Carr AB, McGivney GP, Brown DT, Mc Crackens (2005) Removable partial prosthodontics. (11th edn), Mosby, Missouri. 458.

[4]. BhojarajuN, SrilakshmiJ, VishwanathG (2014) Study of Deflections in Maxillary Major Connectors: A Finite Element Analysis. J Indian Prosthodont Soc. 14(1): 50-60.

[5]. Davenport JC, Basker RM, Health JR, Ralph JP, Glantz PO (2001) Prosthetics: Connectors. Brit Dent J. 190: 184-195.

[6]. Miho E, Noriyuki W, Takashi O (2002) Finite element analysis of the deflections in major connectors for maxillary RPD's. Int J Prosthodont. 25(5): 433-438.

[7]. Antony KK (1956) Effect of partial denture design on bilateral force distribution. J Prosthet Dent. 6(3): 373-385.

[8]. Ben Z, Matalon S, Aviv I, Cardash HS (1989) Rigidity of major connectors when subjected to bending and torsion forces. J Prosthet Dent. 62(5): 557-562.

[9]. Itoh H, Baba K, Aridome K, Okada D, Tokuda A, et al., (2008) Effect of direct retainer and major connector designs on RPD and abutment tooth movement dynamics. J Oral Rehabil. 35(11): 810-815.

[10]. Chandler JA, Brudvik JS (1984) Clinical evaluation of patients eight to nine years after placement of removable partial dentures. J Prosthet Dent. 51(6): 736-743.

[11]. Eto M, Wakabayashi N, Ohyama T (2002) Finite Element Analysis of Deflections in Major Connectors for Maxillary RPDs. Int J Prosthodont. 15(5): 433-8

[12]. Aridome K, Yamazaki M, Baba K, Ohyama T (2005) Bending properties of strengthened $\mathrm{Ti}-6 \mathrm{Al}-7 \mathrm{Nb}$ alloy major connectors compared to $\mathrm{Co}-\mathrm{Cr}$ alloy major connectors. J Prosthet Dent. 93(3): 267-273.

[13]. Taylor DT, Pflughoeft FA, McGivney GP (1982) Effect of two clasping assemblies on arch integrity as modified by base adaptation. J Prosthet Dent. 47(2): 120-125.

[14]. Ozkan P, Aydin AK (2001) Comparison of deformation by stereophotogrammetry of various kinds of major connectors in maxillary Kennedy Class I removable partial dentures. Int J Prosthodont.14(1): 71-76.

[15]. McGivner GP, Carr AB (2000) McCracken's Removable partial prosthodontics. (10th edn) Mosby, U.S.A. 35-58, 445- 447.

[16]. Cohen KD, Faigenblum MJ (1990) An examination of the rigidity of major connectors for removable partial dentures: An in-vitro study investigating horizontal loading of mandibular connectors. Clin Mater. 6(2): 163-179.

[17]. Akaltan F, Kaynak D (2005) An evaluation of the effects of two distal extension removable partial denture designs on tooth stabilization and periodontal health. J Oral Rehabil. 32(11): 823-829.

[18]. Cosme DC, Baldisserotto SM, Fernandes EdeL, RivaldoEG, RosingCK, et al., (2006) Functional evaluation of oral rehabilitation with removable partial dentures after five years.J Appl Oral Sci. 14(2): 111-116.

[19]. Laird RE, Laminie GA (1986) Osborne and Laminie's Partial Dentures. (5th edn), Blackwell Scientific Publications, London. 23-38, 51-72, 273-278

[20]. Harley WT (1972) Dynamic Palatography: A study of linguo-palatal contact during the production of selected consonant sounds. J Prosthet Dent. 27(4): 364-376.

[21]. Polychronakis N, Sotiriou M, Zissis A (2013) A Survey of Removable Partial Denture Casts and Major Connector Designs Found in Commercial Laboratories, Athens, Greece. J Prosthodont. 22(3): 245-249.

[22]. Zeev BU, Eitan M, Colin G, Tamar B (1999) Stiffness of different designs and cross-sections of maxillary and mandibular major connectors of removable partial dentures. J Prosthet Dent. 81(5): 526-532.

[23]. Carr AB, BrownDT (2011) McCracken's Removable partial prosthodontics. (12th edn), Mosby, 45.

[24]. Phoenix RD, Cagna DR, DeFreest CF (2003) Stewart's Clinical Removable Partial Prosthodontics. (4th Edn), Chicago: Quintessence Publ. 25-26.

[25]. Maeda Y, Nokubi T, Okuno Y (1982) Morphological analysis of palate in relation to designing major connectors for removable partial dentures. J Osaka Univ Dent Sch. 22: 193-205.

[26]. Phoenix RD, Cagna DR, DeFreest CF (2003) Stewart's Clinical Removable Partial Prosthodontics. (4th Edn), Chicago: Quintessence Publ. 19-31.

[27]. Inoue T, Oki M, Phankosol P, Ohyama T, Taniguchi H (2002) Vibration analysis of maxillary removable partial denture frameworks. J Oral Rehabil. 29(4): 341-349.

[28]. PhoenixRD, CagnaDR, DeFreestCF (2003) Stewart's clinical removable partial prosthodontics. (4th Edn), Quintessence, Chicago. 525.

[29]. LaVere AM, Krol AJ (1973) Selection of a major connector for the extension-base removable partial denture. J Prosthet Dent. 30(1): 102-105.

[30]. Green LK, Hondrum SO (2003) The effect of design modifications on the torsional and compressive rigidity of U-shaped palatal major connectors. J Prosthet Dent. 89(4): 400-407.

[31]. Potter RB, Appleby RC, Adams CD (1967) Removable partial denture design: a review and a challenge. J Prosthet Dent. 17(1): 63-68.

[32]. Daniel RE, Granata JS (1985) The rotational-path removable partial denture. Compend Contin Educ Dent. 6(10): 716, 720-722.

[33]. Jacobson TE (1982) Satisfying esthetic demands with rotational path partial dentures. J Am Dent Assoc.105(3): 460-465.

[34]. McGivney GP, Carr AB (1999) McCracken's removable partial prosthodontics. (10th edn), St. Louis: Mosby. 35.

[35]. Kaires AK (1956) Effect of partial denture design on bilateral force distribution. J Prosthet Dent. 6(3): 373-385.

[36]. DeFranco RL (1984) Designing removable partial dentures. Dent Clin North Am. 28(2): 307-325.

[37]. Ramakrishnan H, Singh RG (2010) Three-dimensional finite element analysis of the stress distribution pattern in the design modifications of U-shaped palatal major connector. Indian J Dent Res. 21(4): 506-511.

[38]. O"wall BE, Taylor RL (1989) A survey of dentitions and removable partial dentures constructed for patients in North America. J Prosthet Dent. 61(4): 465-470.

[39]. Curtis DA, Curtis TA, Wagnild GW, Finzen FC (1992) Incidence of various classes of removable partial dentures. J Prosthet Dent. 67(5): 664-667.

[40]. Owall BE, Bieniek KW, Spiekermann H (1995) Removable partial denture production in western Germany. Quintessence Int. 26(9): 621-627.

[41]. AL-Dwairi ZN (2006) Partial edentulism and removable denture construction: a frequency study in Jordanians. Eur J Prosthodont Restor Dent. 14(1): 13-17.

[42]. Takanashi T, Shimamura I, Sakurai K (2009) Influence of width and depth of palatal vault on rigidity of palatal strap: A finite element study. J Prosthodont Res. 53(2): 95-100

[43]. Pallegama RW, Namano S, Aridome K, Baba K, Purnaveja S, et al., (2006) Do patients have a preference for major connector designs? J Contemp Dent Pract. 7(5): 71-79.

[44]. Hallikerimath RB, Mallikarjun HD, Patil V, Kumar VS (2015) Evaluation of deflection in single palatal strap major connector as influenced by different shapes of palatal vault: A three-dimensional finite element study. J Int Oral Heath. 7(10): 53-57.

[45]. Campbell LD (1977) Subjective reactions to major connector designs for removable partial dentures. J Prosthet Dent. 37(5): 507-516.

[46]. Pun DK, Waliszewski MP, Waliszewski KJ, Berzins D (2011) Survey of partial removable dental prosthesis (partial RDP) types in a distinct patient population. J Prosthet Dent. 106(1): 48-56.

[47]. Arthur ML, Arthur JK (1973) Selection of a major connector for the extension base removable partial denture. J Prosthet Dent. 30(1): 102-105.

[48]. Barbenel JC (1971) Design of partial denture components I. Middle palatal bars. J Dent Res. 50(3): 586-589.

[49]. Anan MT, Al-Saadi MH (2015) Fit accuracy of metal partial removable dental prosthesis frameworks fabricated by traditional or light curing modeling material technique: An in vitro study. Saudi Dental J. 27(3): 149-154.

[50]. Bhathal M, Batra J, Attresh G, Sambyal S (2015) A review on stressesinduced by removable partial dentures. Int J Contemp Dent Med Rev. 050115: 5 . 
[51]. Owall B, Budtz-Jörgensen E, Davenport J, Mushimoto E, Palmqvist S, et al., (2002) Removable partial denture design: a need to focus on hygienic principles? Int J Prosthodont. 15(4): 371-378.

[52]. Bates JF, Huggett R, Stafford GD (1991) Removable Denture Construction. (3rd Edn), London, Wright. 20(4): 254.

[53]. Bissada NF, Ibrahim SI, Barsoum WM (1974) Gingival response to various types of removable partial dentures. J Periodontol. 45(9): 651-659.

[54]. Orr S, Linden GJ, Newman HN (1992) The effect of partial denture connectors on gingival health. J Clin Periodontol.19(8): 589-594.

[55]. Boucher LJ, Renner RP (1982) Treatment of partially edentulous patients. St Louis: CV Mosby Co. 44-52.

[56]. Henderson D, Steffel VL (1977) McCracken's removable partial prosthodontics. (5th edn), Louis: CV Mosby Co. 19-44.

[57]. Berg E (1987) Periodontal problems associated with use of distal extension removable partial dentures - A matter of construction. J Prosthet Dent. 12(5): 369-79.

[58]. Cecconi BT, Asgar K, Dootz E (1971) The effect of partial denture clasp design on abutment tooth movement. J Prosthet Dent. 25(1): 44-56.

[59]. Bergman B (2002) Periodontal reactions related to removable partial dentures: A literature review. J prosthet Dent. 58(4): 454-8.

[60]. Bergman B, Hugoson A, Olsson CO (1977) Caries and periodontal status in patients fitted with removable partial dentures. J Clin Periodontol. 4(2): 134-146.

[61]. Preshaw PM, Walls AW, Jakubovics NS, Moynihan PJ, Jepson NJ, et al., (2011) Association of removable partial denture use with oral and systemic health. J Dent. 39(11): 711-719.

[62]. Jorge JH, Quishida CC, Vergani CE, Machado AL, Pavarina AC, et al., (2012) Clinical evaluation of failures in removable partial dentures. J Oral Sci. 54(4): 337-342.
[63]. Arigbede AO, Dosumu OO, Esan TA, Akeredolu PA (2006) Acceptability of maxillary major connectors in removable partial dentures. Afr Health Sci. 6(2): 113-117.

[64]. Pallegama RW, Aridome K, Baba K, Ohyama T (2005) Patients' preference for acrylic resin major connector analogues formulated for titanium alloy removable partial dentures. J Med Dent Sci. 52(2): 123-128.

[65]. Frantz WR(1973) Variability in dentists designs of a removable maxillary partial denture. J Prosth Dent. 29(2): 172- 173.

[66]. Frank RP, Brudvik JS, Leroux B, Milgrom P, Hawkins N (2000) Relationship between the standards of removable partial denture construction, clinical acceptability, and patient satisfaction. J Prosthet Dent. 83(5): 521-527.

[67]. Koyama S, Sasaki K, Yokoyama M, Sasaki T, Hanawa S (2010) Evaluation of factors affecting the continuing use and patient satisfaction with removable partial dentures over 5 years. J Prosthodont Res. 54(2): 97-101.

[68]. Wagner AG, Traweek FC (1982) Comparison of major connectors for removable partial dentures. J Prosthet Dent. 47(3): 242-245.

[69]. Wada J, Hideshima M, Inukai S, Matsuura H, Wakabayashi N (2014) Influence of the width and cross-sectional shape of major connectors of maxillary dentures on the accuracy of speech production. Folia Phoniatr Logop. 66(6): 227-236.

[70]. Wada J, Hideshima M, Inukai S, Ando T, Igarashi Y, Matsuura H (2011) Influence of the major connector in a maxillary denture on phonetic function. J Prosthodont Res. 55(4): 234-242.

[71]. Farrel J (1969) Partial denture tolerance. Dent Pract. 19(5): 162-164.

[72]. Clark JW (1984) Clinical Dentistry. Volume 5 Revised edn, Philadelphia: Harper and Row. Publishers, chlp 1- 2, 11 -12, ch7p 1-3.

[73]. Walter JD (1980) Partial Denture Technique - Connectors. Br Dent J. 148(5): 133-134. 